\title{
Research on Competitiveness Evaluation Index System of Cultural Tourism Enterprises in the Guangdong-Hong Kong-Macao Greater Bay Area
}

\author{
Chuhan Wong, Yirun Chen, Mu Zhang* \\ Shenzhen Tourism College of Jinan University, Shenzhen, China \\ Email: sharonchuhan@163.com, *zhangmu@jnu.edu.cn
}

How to cite this paper: Wong, C.H., Chen, Y.R. and Zhang, M. (2019) Research on Competitiveness Evaluation Index System of Cultural Tourism Enterprises in the Guangdong-Hong Kong-Macao Greater Bay Area. Journal of Service Science and Management, 12, 573-588.

https://doi.org/10.4236/jssm.2019.125039

Received: June 3, 2019

Accepted: August 2, 2019

Published: August 5, 2019

Copyright $\odot 2019$ by author(s) and Scientific Research Publishing Inc. This work is licensed under the Creative Commons Attribution International License (CC BY 4.0).

http://creativecommons.org/licenses/by/4.0/

\begin{abstract}
As the most free-spirited and open economic zone in China, the Guangdong-Hong Kong-Macao Greater Bay Area is constructed towards the destination as a quality living circle for living, working and travelling. The integration of culture and tourism is a new business format derived from the construction, which also supports the system architecture of cultured bay area. This paper selects the practitioners of the business format as the research subject, and constructs the competitiveness evaluation index system of cultural tourism enterprises in Guangdong-Hong Kong-Macao Greater Bay Area through Delphi method and Analytic Hierarchy Process from five dimensions of resource endowment, financial operation, cultural creativity and technology, regional environment and potential development, taking Guangzhou Lingnan Group, Shenzhen Overseas Chinese Town and China Travel HK as the empirical test objects. According to the test results and analysis, the research proposes the path for enhancing competitiveness of cultural tourism enterprises under the new circumstances and discusses the future development.
\end{abstract}

\section{Keywords}

Guangdong-Hong Kong-Macao Greater Bay Area, The Integration of Culture and Tourism, Enterprise Competitiveness

\section{Introduction}

Bay area economy is the most important model of contemporary coastal economy, which has been implemented successfully throughout the world. However, 
the similar natural conditions and development process have created various successful models on account of different blueprints and directions. In 2016, the Guangdong-Hong Kong-Macao Greater Bay Area that has been explicitly clarified in the Thirteenth Five-Year Plan for Economic and Social Development consists of two special administrative regions and nine cities in Guangdong [1], playing the strategic roles as the forerunner of China's reform and opening up and the growth pole for the economic development. In order to construct an international first-class Bay Area with industrial structure optimization and innovation capability, the Outline Development Plan for the Guangdong-Hong Kong-Macao Greater Bay Area issued by the State Council in 2019 states: To promote the development of tourism in the Greater Bay Area, leverage the characteristic advantages of the Greater Bay Area and Hong Kong's status as an international transportation center, develop a system with diverse tourism products including culture and history, leisure and vacation, establish the Greater Bay Area as a world-class tourism destination [2].

Globally there are three well-known Bay Areas: developed manufacturing industry and high-level urbanization have achieved the Tokyo Bay Area, the New York Bay Area is famous for financial center and artistic design, and in the San Francisco Bay Area, high-tech industries, international trade and tourism strengthen its influence. Compared with these Bay Areas, the Guangdong-Hong Kong-Macao Greater Bay Area has a complex pattern of "one country, two systems, three currencies, and three customs territories". However, multi-culture represented by Lingnan culture in the Greater Bay Area integrates into this peculiar pattern, generating new cultural formats. In the future, with the construction of the Greater Bay Area, the Belt and Road Initiative, Portuguese culture and Spanish culture in Hong Kong and Macao, all together will replenish more vibrant benefits for the cultural industries in the Greater Bay Area.

According to the China Statistical Yearbook on Culture and Related Industries and Statistical Analysis Report on Cultural Development, in 2016, the added value of cultural industries in Guangdong reached 425.66 billion yuan, and the value of cultural industry output accounted for 5.26\% of Guangdong's GDP. In 2017, the growth rate of the added value of cultural industries in Guangdong outpaced the growth rate of GDP, which indicates that Guangdong's emerging cultural formats maintain a leading position in the country. The outstanding performance is credited to the open and innovative culture and continuously expanding industry boundaries. Relying on the advanced Internet technologies, new models such as "culture plus finance", "culture plus technology" and "culture plus tourism" are reshaping the cultural industry structure.

With the new era of mass tourism, tourism products preferred by tourists contain rich cultural connotations, and are no longer simple symbolic duplication. In the Greater Bay Area, there are cross-industrial leading enterprises such as China Travel HK, Guangdong Changlong Group, Shenzhen Overseas Chinese Town that excavate the industrial chain value, and vital small and medium tourism enterprises pool together. Furthermore, Tencent creates Tencent Culture 
and Tourism derived from the exploration of "Internet plus Tourism" in the context of the digital economy. For cultural tourism enterprises as the innovative subject of "Culture plus Tourism" new business format, how to evaluate their competitiveness scientifically and objectively is a crucial proposition for exploring the development direction of the new cultural format in the Guangdong-Hong Kong-Macao Greater Bay Area.

The article is organized as follows, this paper takes the competitiveness of cultural tourism enterprises in the Guangdong-Hong Kong-Macao Greater Bay Area as the research object, constructs an evaluation index system through Delphi method, uses analytic hierarchy process (AHP) to determine the weight of each dimension and element, and selects typical cultural tourism enterprises in GBA to conduct empirical comparative analysis, finally provides suggestions for the future development of GBA (Figure 1).

\section{Literature Review}

\subsection{Research Status of Evaluation System}

Chinese scholars have designed relevant evaluation systems. Xu Chunxiao et al. (2008) used dynamic set pair identical degree analysis and dynamic factor analysis to empirically evaluate the competitiveness of China's tourism listed companies. They constructed the evaluation system by selecting 11 financial indicators that reflected the company's competitive performance, amongst which the dynamic competitiveness reflected long-term performance that is greatly influenced by profitability, solvency, operational capacity and potential factors [3]. Gao Li et al. (2008) combined the principal component analysis with fuzzy comprehensive evaluation method to select 19 indexes included in 5 factors of benefit, scale, growth, management and popularity to create a competitiveness evaluation model. Their analysis result shows that the resource-based enterprises are the most competitive in tourism industry [4]. Ge Hongpeng (2008) believed

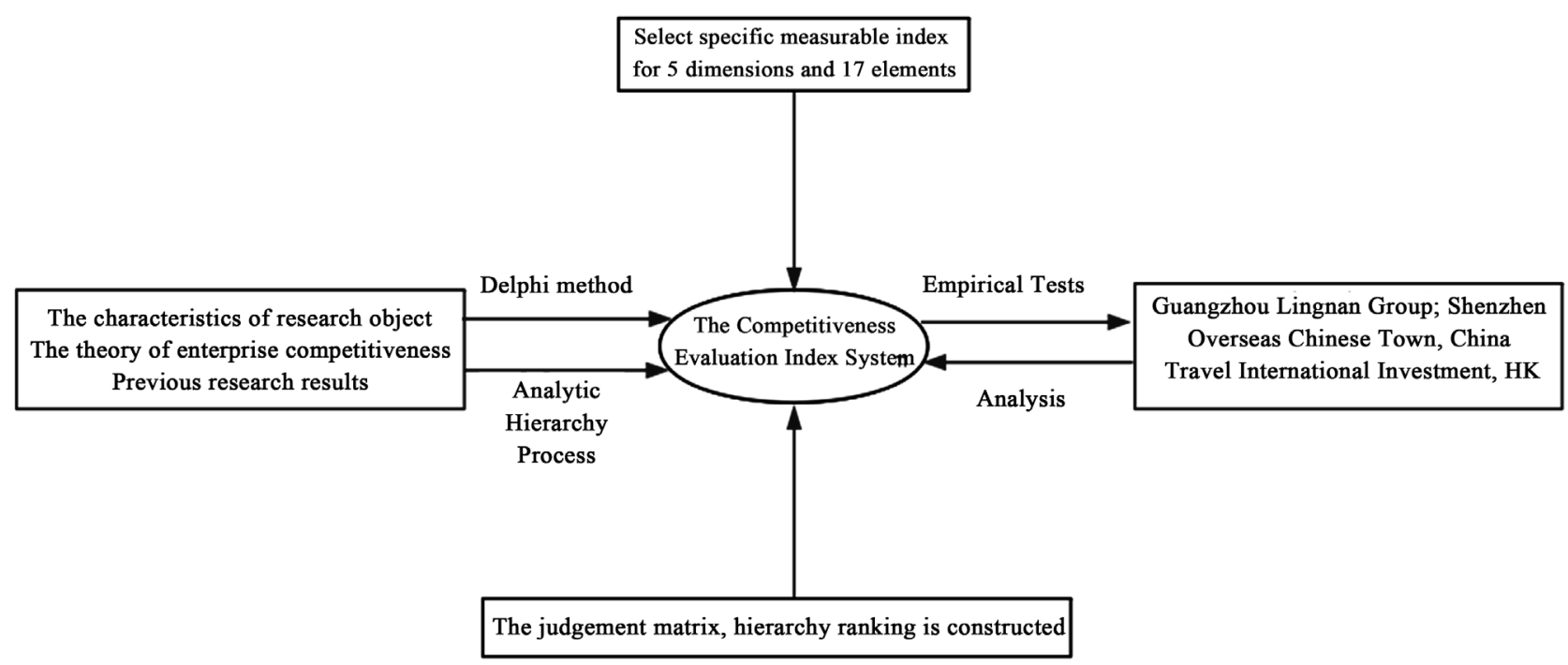

Figure 1. The structure of this paper. 
that the competitiveness of tourism enterprises is composed of four major factors: resource endowment, regional environment, management and development ability, and he used AHP to calculate factor weights and enterprise competitiveness scores [5]. Xie Yu et al. (2010) combined soft-hard indexes and established a tourism enterprise competitiveness evaluation model through ANP [6]. Li Jing et al. (2011) also selected 10quantifiable financial indexesof4 categories, using the entropy weight method and the grey relational analysis to evaluate the competitiveness of tourism listed companies [7]. Zhang Guanghai et al. (2011) integrated new indexes such as agglomerative economies effect and relative density of tourism enterprises into the competitiveness evaluation system of tourism enterprises. Then they used Delphi method and AHP to calculate the weight values of each index which were amended through entropy weight analysis [8]. Yan Youbing et al. (2014) selected 16 indexes from 4 aspects of enterprise scale, performance, service and innovation capability, and calculated the comprehensive competitiveness of 12 online tourism enterprises through entropy weight TOPSIS method [9].

Above reviews show that scholars have adopted a variety of evaluation methods from different perspectives, which are mainly as follows. The comprehensive evaluation method uses a set of indexes to summarize and evaluate the enterprise competitiveness. The objectivity, applicability, and comprehensiveness of the system have great influences on the evaluation result. The index weight of this evaluation system is generally determined through Delphi method. The fuzzy comprehensive evaluation method is specific for handling factors with fuzziness that cannot be simply evaluated, which uses fuzzy mathematics to quantitatively analyze the enterprise competitiveness. Analytic hierarchy process determines the importance coefficient of the indexes in the system to the target by constructing the judgment matrix, which focuses on the practical significance of research objects. The gray relational analysis is applicable for circumstance that there are complicated factors influence the competitiveness of enterprises or some data are not available, which judges whether the correlation is significantly based on the similarity degree of sequence curve geometric shape. The original information in the entropy weight analysis is directly derived from the objective fact, and comparative value of the evaluation object index is calculated, the great difference indicates the large weight.

According to the retrieval result from Chinese National Knowledge Infrastructure, the existing researches on tourism competitiveness are concentrated on urban tourism and tourism industry. However, there are few thoroughgoing researches on the competitiveness of tourism enterprises. In recent years, theoretical achievements of tourism enterprises competitiveness focus on the influences of enterprise resource and main business activities that merely use financial data or enterprise competitiveness index system, or establish evaluation system from the perspective of tourism industry, which leads to problems such as incomprehensive indexes and excessive research scope. There is lack of evaluating cultural tourism enterprises, ignoring the changes in the competitiveness of 
tourism enterprises under the new business format.

\subsection{The Theory of Enterprise Competitiveness}

Stephen H. Hymer first proposed the concept of enterprise competitiveness in the 1960s, but did not conduct in-depth research. In the early 1980s, Porter believed that five basic forces in the industrial environment are the bargaining power of suppliers, the bargaining power of buyers, the threat of new entrants, the substitutes and the competitive rivalry that determine the industrial profitability and proposed three major strategies for enterprises to build competitive advantages, including overall cost leadership, differentiation strategy and market focus [10]. In the late 1980s and early 1990s, Chinese academia started studying enterprise competitiveness, influenced by the Structural School, the initial research contents were mostly industrial analysis.

Among enterprises there exist differences of tangible resources, intangible resources and specialized resources (Wernerfelt 1984) [11]. Enterprises can develop a competitive advantage by improving the quality of own resources or utilizing resources more efficiently than their opponents. When they are difficult to be imitated or substituted, the advantage is sustainable (Barney 1991) [12]. Collis and Montgomery (1995) argued that the evaluation of resource should not be limited to internal enterprise, but be placed in its industrial environment and compared with its competitors' resources to judge the strength and weakness of the enterprise. Inimitability, durability, appropriability, substitutability, competitive superiority are five tests that indicate the overall state of an enterprise's resources [13]. Early 21st century, Chinese scholars paid attention to Resource School's view and explored how to effectively allocate enterprise resources, especially important resources.

Prahalad et al. (1990) proposed the core competence theory of enterprise regarded enterprises as a competence system and emphasized the significance of resource integration for enterprise competitiveness [14]. Chandler et al. (1994) ascribed the driving force of enterprise development to the organizational capability [15]. Hamel et al. (1994) believed that the key link of business process is the source of enterprises competitive advantage [16]. In the late 1990s, Chinese scholars noticed the exclusive endogenous capacity of an enterprise that can satisfy consumers personalized demand, facilitates the enterprise in the market to acquire long-term advantage and steady profits.

Compared with foreign researches on enterprise competitiveness, China has a later start in both conceptual theory studies and practical management application. However, many scholars have explored some special aspects of China's enterprises based on foreign theoretical systems, in order to find an evaluation system applicable to today enterprises. Jin Pei is one of the earliest scholars who did systematic research on the competitiveness of enterprises in China. His evaluation system includes evaluative index and analytical index [17]. He argued that steady economic growth is beneficial to the improvement 
of enterprise performance after analyzing China's economic trends and corresponding policies in the past 30 years [18]. Hu Ping et al. (2013) found that the external network of an enterprise can directly or through enterprise internal resources affect its competitiveness [19]. China is experiencing an economic transformation, besides the resource exploitation and planning, the environmental factors of enterprise competitiveness such as knowledge management, value creation, cultural atmosphere, macroeconomic control, and international situation should also be taken seriously.

With the continuous complement of research theory and evaluation system, the research methods of enterprise competitiveness are also deviated from the classical economics analytical paradigm synchronously with the expansion of research perspective. Scholars are attempting to combine the evaluation with a practical situation to describe the characteristics of enterprise, in order to make the system apply in various social activities.

\section{Methodology}

\subsection{The Evaluation Index System}

According to the filed research of cultural tourism enterprises, this paper analyzes and concludes high-frequency elements appearing in the representative model or index system based on the characteristics of research objects, the theory of enterprise competitiveness and previous research results, and uses Delphi method to determine 5 dimensions and 17 elements which reflect competitiveness of cultural tourism enterprises in the Guangdong-Hong Kong-Macao Greater Bay Area. Then it selects specific measurable indexes on the principles of science, system and data availability to construct an evaluation index system as shown in Table 1.

\subsection{The Analytic Hierarchy Process}

This paper uses AHP to measure the weight of system indexes. AHP is developed by operational research expert Thomas L. Saaty from the United States, which combines qualitative and quantitative research to represent complicated decision-making in an ordered hierarchy structure, and conducts multi-criteria decision-making through subjective judgement and scientific calculation. AHP simulates the thinking process when people make decisions, and uses mathematics to reflect the weight of various factors, which is suitable for solving realistic problems. According to the evaluation index system constructed in this paper, the subjective data is the rational assignment on the importance of indexes from 16 experts and scholars in the departments of tourism and business management of key universities in Guangdong, and the judgment matrix, hierarchical single ranking and consistency check of evaluation index is constructed layer by layer.

1) This paper adopts a 1 to 9 fundamental scale proposed by Satty. The value of $a_{i j}$ is $1,2, \cdots, 9$ and its reciprocal value is $1,1 / 2, \cdots, 1 / 9$. Compare the subject 
Table 1. The competitiveness evaluation index system of cultural tourism enterprises in Guangdong-Hong Kong-Macao greater bay area.

\begin{tabular}{|c|c|c|c|}
\hline Target & Dimension & Element & Index \\
\hline & \multirow{5}{*}{ Resource endowment $B_{1}$} & Tourism resource $\mathrm{C}_{1}$ & $\begin{array}{l}\text { The number of tourism destinations, the } \\
\text { number of AAAAA level tourist attractions }\end{array}$ \\
\hline & & Human resource $\mathrm{C}_{2}$ & $\begin{array}{l}\text { The number of employees, the quality } \\
\text { of employees }\end{array}$ \\
\hline & & Capital resource $\mathrm{C}_{3}$ & Total assets, total revenues, net income \\
\hline & & Cultural resource $\mathrm{C}_{4}$ & $\begin{array}{l}\text { The number of cultural heritages, } \\
\text { the form of objective culture }\end{array}$ \\
\hline & & Profitability $\mathrm{C}_{5}$ & $\begin{array}{l}\text { Main operating profit ratio, } \\
\text { return on equity, earning per share }\end{array}$ \\
\hline & \multirow[t]{3}{*}{ Financial operation $\mathrm{B}_{2}$} & Growth ability $\mathrm{C}_{6}$ & $\begin{array}{l}\text { Growth rate of main operation, growth rate } \\
\text { of total assets, growth rate of net assets }\end{array}$ \\
\hline & & Risk-control ability $\mathrm{C}_{7}$ & Current ratio, quick ratio, asset-liability ratio \\
\hline & & Capital-operate ability $\mathrm{C}_{8}$ & $\begin{array}{l}\text { Total assets turnover, fixed assets turnover, } \\
\text { inventory turnover }\end{array}$ \\
\hline The Competitiveness & \multirow{3}{*}{ Cultural creativity and technology $\mathrm{B}_{3}$} & Cultural derivatives $\mathrm{C}_{9}$ & $\begin{array}{l}\text { Original cultural Intellectual Property, } \\
\text { the types of cultural souvenir }\end{array}$ \\
\hline $\begin{array}{l}\text { of Cultural Tourism } \\
\text { Enterprises in } \\
\text { Guangdong-Hong } \\
\text { Kong-Macao }\end{array}$ & & Technological research $\mathrm{C}_{10}$ & $\begin{array}{l}\text { The proportion of Research and } \\
\text { Development investment in the operating } \\
\text { income, the proportion of } R \& D \text { personnel }\end{array}$ \\
\hline \multirow[t]{7}{*}{ Greater Bay Area } & & Innovation cluster $\mathrm{C}_{11}$ & $\begin{array}{l}\text { Agglomerative economies effect, the } \\
\text { proportion of achievements application }\end{array}$ \\
\hline & \multirow{3}{*}{ Regional environment $\mathrm{B}_{4}$} & Infrastructure $\mathrm{C}_{12}$ & The number of hotels, traffic accessibility \\
\hline & & Policies and regulations $\mathrm{C}_{13}$ & $\begin{array}{l}\text { Local government general budgetary } \\
\text { expenditure, regulation and supervision }\end{array}$ \\
\hline & & Degree of openness $\mathrm{C}_{14}$ & $\begin{array}{l}\text { Overnight international tourists, } \\
\text { total foreign exchange earnings from } \\
\text { international tourism }\end{array}$ \\
\hline & \multirow{3}{*}{ Potential development $\mathrm{B}_{5}$} & Enterprise image $C_{15}$ & $\begin{array}{l}\text { Service quality of enterprise, } \\
\text { tourist satisfaction }\end{array}$ \\
\hline & & Market demand $\mathrm{C}_{16}$ & $\begin{array}{l}\text { Per capita disposable income of permanent } \\
\text { households, per capita expenditure on } \\
\text { recreation and cultural service over } \\
\text { total consumption expenditure }\end{array}$ \\
\hline & & Industry's position $\mathrm{C}_{17}$ & $\begin{array}{l}\text { The proportion of gross output value of } \\
\text { tourism in the regional GDP, growth rate of } \\
\text { added value of cultural and creative industry }\end{array}$ \\
\hline
\end{tabular}

layers according to the same criterion, and construct a judgment matrix.

2) If there are $N$ elements $\left(C_{1}, C_{2}, \cdots, C_{i}, \cdots, C_{n}\right)$, then its comparison matrix is $A=\left(a_{i j}\right)$, and $a_{i j}$ is the relative importance of $C_{i}$ to $C_{j}$. The relative weight $W_{i}$ of $C_{i}$ is calculated through the formula $W_{i}=\sum_{j=1}^{n}\left(a_{i j} / \sum_{i=1}^{n} a_{i j}\right) / n, \forall i, j=1,2, \cdots, n$. When the comparison matrix $A$ is consistent, the normalized eigenvector $\mathrm{W}$ of 
the eigenvalue $\lambda_{\max }=n$ of $A$ is a weight vector, that is, the weight vector satisfies: $A W=\lambda_{\max } W, \sum_{i=1}^{n} W_{i}=1$. In reality, if the judgment matrix does not have the consistency, its maximum eigenvalue $\lambda_{\max } \neq n$, which can be calculated by $A W=\lambda_{\max } W, \lambda_{\max }=\frac{1}{n} \sum_{i=1}^{n}(A W)_{i} / W_{i}$.

3) Due to various factors and subjective tendency, the comparison matrix is usually not consistent, but the degree of inconsistency should be within the allowable range. $C I$ is the consistency index, and set $C I=\left(\lambda_{\max }-n\right) /(n-1)$. When $C I=0$, the matrix is consistent. The larger the $C I$, the more serious the inconsistency of the matrix. $C R$ is the consistency ratio, and set $C R=C I / R I$, where $R I$ is the random consistency index, and its values are shown in Table 2. When $C R=C I / R I>0.10$, the matrix has no consistency; when $C R=C I / R I<0.10$, the inconsistency of the matrix is considered to be within the allowable range, and the normalized eigenvector of the comparison matrix is used as the weight vector that is the hierarchical ranking weight.

The A-B dimensional layer matrix and hierarchical ranking results of the competitiveness of cultural tourism enterprises in Guangdong-Hong Kong-Macao Greater Bay Area are shown in Table 3.

The dimension $\mathrm{B}_{1}-\mathrm{C}$ matrix and hierarchical single ranking are listed in Table 4.

Table 2. Random consistency Index (RI).

\begin{tabular}{|c|c|c|c|c|c|c|c|c|c|c|c|}
\hline & 1 & 2 & 3 & 4 & 5 & 6 & 7 & 8 & 9 & 10 & 11 \\
\hline RI & 0 & 0 & 0.58 & 0.90 & 1.12 & 1.24 & 1.32 & 1.41 & 1.45 & 1.49 & 1.51 \\
\hline
\end{tabular}

Table 3. Pairwise comparison matrix and relative weight results for dimensions and impact on target.

\begin{tabular}{cccccccc}
\hline $\mathrm{A}$ & $\mathrm{B}_{1}$ & $\mathrm{~B}_{2}$ & $\mathrm{~B}_{3}$ & $\mathrm{~B}_{4}$ & $\mathrm{~B}_{5}$ & $\mathrm{~W}$ & Ranking \\
\hline $\mathrm{B}_{1}$ & 1 & 2 & 2 & 4 & 5 & 0.3850 & 1 \\
$\mathrm{~B}_{2}$ & $1 / 2$ & 1 & $1 / 2$ & 3 & 4 & 0.2010 & 3 \\
$\mathrm{~B}_{3}$ & $1 / 2$ & 2 & 1 & 3 & 4 & 0.2664 & 2 \\
$\mathrm{~B}_{4}$ & $1 / 4$ & $1 / 3$ & $1 / 3$ & 1 & 2 & 0.0895 & 4 \\
$\mathrm{~B}_{5}$ & $1 / 5$ & $1 / 4$ & $1 / 4$ & $1 / 2$ & 1 & 0.0580 & 5 \\
\hline
\end{tabular}

$\lambda=5.1116, \mathrm{CI}=0.0279, \mathrm{RI}=1.12, \mathrm{CR}=0.0249<0.10$.

Table 4. Ranking list of element weight of dimension $\mathrm{B}_{1}-\mathrm{C}$.

\begin{tabular}{ccccccc}
\hline $\mathrm{B}_{1}$ & $\mathrm{C}_{1}$ & $\mathrm{C}_{2}$ & $\mathrm{C}_{3}$ & $\mathrm{C}_{4}$ & $\mathrm{~W}$ & Ranking \\
\hline $\mathrm{C}_{1}$ & 1 & 3 & $1 / 2$ & 2 & 0.2844 & 2 \\
$\mathrm{C}_{2}$ & $1 / 3$ & 1 & $1 / 4$ & $1 / 3$ & 0.0872 & 4 \\
$\mathrm{C}_{3}$ & 2 & 4 & 1 & 2 & 0.4279 & 1 \\
$\mathrm{C}_{4}$ & $1 / 2$ & 3 & $1 / 2$ & 1 & 0.2005 & 3
\end{tabular}

$\lambda=4.0813, \mathrm{CI}=0.0271, \mathrm{RI}=0.90, \mathrm{CR}=0.0304<0.10$. 
The dimension $\mathrm{B}_{2}-\mathrm{C}$ matrix and hierarchical single ranking are listed in $\mathrm{Ta}-$ ble 5 .

The dimension $\mathrm{B}_{3}-\mathrm{C}$ matrix and hierarchical single ranking are listed in $\mathrm{Ta}-$ ble 6 .

The dimension $\mathrm{B}_{4}-\mathrm{C}$ matrix and hierarchical single ranking are listed in Table 7 .

The dimension $\mathrm{B}_{5}-\mathrm{C}$ matrix and hierarchical single ranking are listed in $\mathrm{Ta}-$ ble 8 .

The results show that the judgement matrix of each hierarchical layer indexes passes the consistency check, indicating that the weight values can be adopted. Therefore, the weights of elements and corresponding dimensional layers B1, B2, B3, B4, and B5 are weighted, and the combined weights of indexes are calculated, the final evaluation index system and weights are shown in Table 9.

Table 5. Ranking list of element weight of dimension $\mathrm{B}_{2}-\mathrm{C}$.

\begin{tabular}{ccccccc}
\hline $\mathrm{B}_{2}$ & $\mathrm{C}_{5}$ & $\mathrm{C}_{6}$ & $\mathrm{C}_{7}$ & $\mathrm{C}_{8}$ & $\mathrm{~W}$ & Ranking \\
\hline $\mathrm{C}_{5}$ & 1 & 2 & 4 & 3 & 0.4717 & 1 \\
$\mathrm{C}_{6}$ & $1 / 2$ & 1 & 2 & 2 & 0.2562 & 2 \\
$\mathrm{C}_{7}$ & $1 / 4$ & $1 / 2$ & 1 & $1 / 2$ & 0.1078 & 4 \\
$\mathrm{C}_{8}$ & $1 / 3$ & $1 / 2$ & 2 & 1 & 0.1644 & 3 \\
\hline
\end{tabular}

$\lambda=4.0458, \mathrm{CI}=0.0153, \mathrm{RI}=0.90, \mathrm{CR}=0.0172<0.10$.

Table 6. Ranking list of element weight of dimension $B_{3}-C$.

\begin{tabular}{cccccc}
\hline $\mathrm{B}_{3}$ & $\mathrm{C}_{9}$ & $\mathrm{C}_{10}$ & $\mathrm{C}_{11}$ & $\mathrm{~W}$ & Ranking \\
\hline $\mathrm{C}_{9}$ & 1 & $1 / 2$ & 3 & 0.3090 & 2 \\
$\mathrm{C}_{10}$ & 2 & 1 & 5 & 0.5816 & 1 \\
$\mathrm{C}_{11}$ & $1 / 3$ & $1 / 5$ & 1 & 0.1095 & 3 \\
\hline
\end{tabular}

$\lambda=3.0037, \mathrm{CI}=0.0019, \mathrm{RI}=0.58, \mathrm{CR}=0.0036<0.10$.

Table 7. Ranking list of element weight of dimension $\mathrm{B}_{4}-\mathrm{C}$.

\begin{tabular}{cccccc}
\hline $\mathrm{B}_{4}$ & $\mathrm{C}_{12}$ & $\mathrm{C}_{13}$ & $\mathrm{C}_{14}$ & $\mathrm{~W}$ & Ranking \\
\hline $\mathrm{C}_{12}$ & 1 & $1 / 2$ & 2 & 0.3108 & 2 \\
$\mathrm{C}_{13}$ & 2 & 1 & 2 & 0.4934 & 1 \\
$\mathrm{C}_{14}$ & $1 / 2$ & $1 / 2$ & 1 & 0.1958 & 3 \\
\hline
\end{tabular}

$\lambda=3.0536, \mathrm{CI}=0.0268, \mathrm{RI}=0.58, \mathrm{CR}=0.0516<0.10$.

Table 8. Ranking list of element weight of dimension $\mathrm{B}_{5}-\mathrm{C}$.

\begin{tabular}{cccccc}
\hline $\mathrm{B}_{4}$ & $\mathrm{C}_{15}$ & $\mathrm{C}_{16}$ & $\mathrm{C}_{17}$ & $\mathrm{~W}$ & Ranking \\
\hline $\mathrm{C}_{15}$ & 1 & 3 & 2 & 0.5396 & 1 \\
$\mathrm{C}_{16}$ & $1 / 3$ & 1 & $1 / 2$ & 0.1634 & 3 \\
$\mathrm{C}_{17}$ & $1 / 2$ & 2 & 1 & 0.2970 & 2 \\
\hline
\end{tabular}

$\lambda=3.0092, \mathrm{CI}=0.0046, \mathrm{RI}=0.58, \mathrm{CR}=0.0088<0.10$. 
Table 9. Index weight of evaluation system of the competitiveness of cultural tourism enterprises in Guangdong-Hong Kong-Macao greater bay area.



\section{Empirical Analysis}

\subsection{Data Sources}

Based on the evaluation index system constructed, this paper selects Guangzhou Lingnan Group Co. Ltd., Shenzhen Overseas Chinese Town (OCT) Co. Ltd. and China Travel International Investment HK LTD as the empirical test objects. The three enterprises place different emphases on the tourism industry. In order to ensure the consistency of statistical analysis and the authority of data, the data sources in this research are from normative statistical materials such as the 2018 Statistical Yearbook of Chinese Cities, the 2018 Hong Kong Annual Digest of Statistics, and the 2018 annual report of listed companies. Partial indexes are calculated by corresponding formulas, and all the original data is processed to be consistent and dimensionless.

\subsection{Index Calculation and Analysis}

From the dimension of resource endowment, the element index of three enterprises is shown in Figure 2. The Lingnan Group's headquarters is located in Guangzhou, and its businesses include hotels, exhibitions and travel agencies that rely on a wealth of tourism and cultural resources. OCT is founded in Shenzhen, starting from its headquarters, OCT has extended to Guangzhou, Zhuhai, Huizhou, etc. Its tourism business covers more than 50 cities in China 


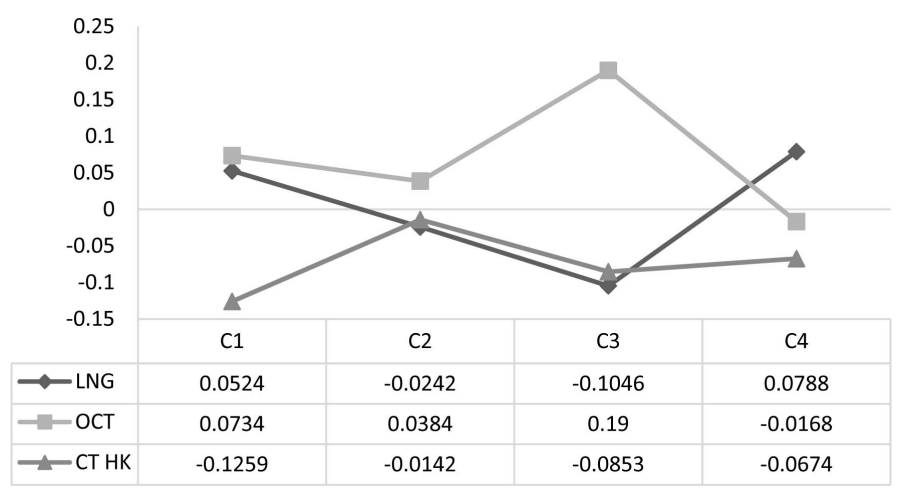

Figure 2. The element index of enterprise resource layer.

with all-region travelling projects and new urbanization projects, establishing a variety of cultural tourism formats such as theme parks, eco-tourism resorts and urban leisure areas, and OCT has sufficient tourism and capital resources. Due to the influence of spatial resources, CT HK has a poor performance in these elements.

From the dimension of financial operation, Lingnan Group is efficient in the asset utilization and management, with better capital turnover condition. OCT and CT HK have stronger profitability and growth ability, showing that the two are continuously expanding their market share and have good adaptability in business activities. The specific index of each element is shown in Figure 3.

The element index calculated in the innovation dimension is shown in Figure 4. OCT currently owns the industry-leading cultural tourism brands such as Happy Valley, Splendid China, and Window of the World, and derives original cultural IP from existing resources. For example, the image of "Little Hakka" is displayed through "IP + VR" in Gankeng Hakka New Town. CT HK has a large proportion of R\&D investment and focuses on the enterprise information technology.

This paper uses Location Quotient proposed by Haggett to measure the agglomerative economies effect, which can reflect the level of specialization of an industry in a certain region [20]. The calculation formula is

$$
L Q_{i t}=\frac{Y_{i t}}{G D P_{i t}} / \frac{Y_{i}}{G D P_{i}}
$$

where $L Q_{i t}$ refers to the location quotient of iregion during $t$ period, which is calculated by dividing the proportion of added value of scientific research and technical service industry in iregion GDP during $t$ period by the proportion of output value of scientific research and technical service industry in one space GDP during $t$ period. A greater $L Q_{i t}$ value indicates a higher agglomerative degree. The LQ values of three enterprises have a small difference that they are close to or greater than 1, reflecting that the innovation agglomerative degree of the region is equal to or higher than the average level of the space.

The regional environment is measured by urban infrastructure, fiscal expenditure, and the number of international tourists in the region where the enterprise 


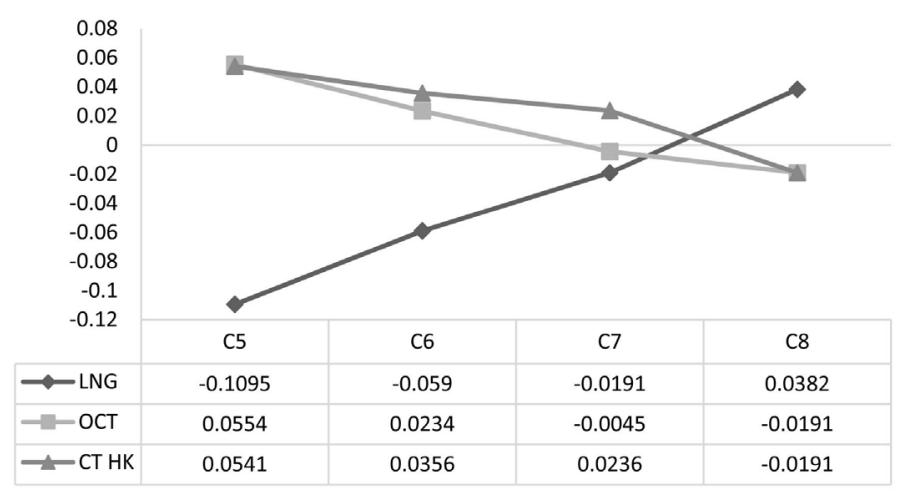

Figure 3. The element index of enterprise financial layer.

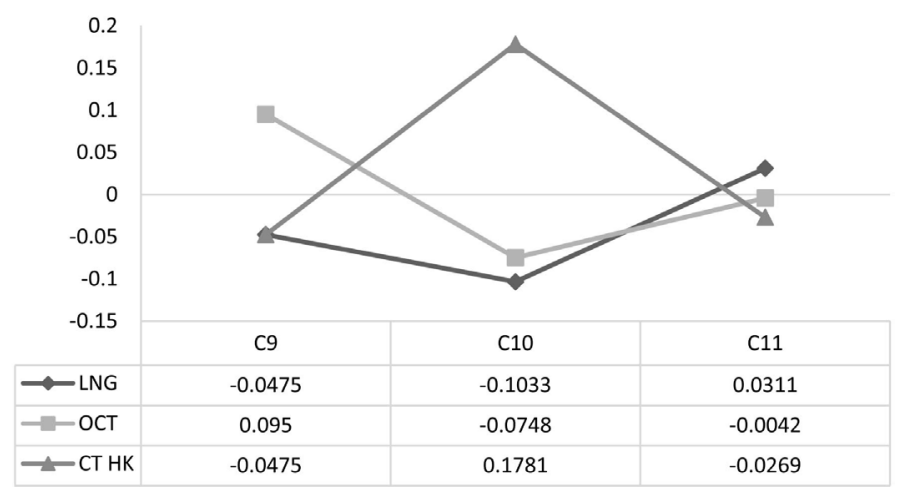

Figure 4. The element index of enterprise innovation layer.

is located. The results are shown in Figure 5. Guangzhou plays a role as an integrated transportation hub and a comprehensive gateway city with reasonable facilities. Shenzhen has a high government budget which gives a strong support for the tourism industry. As a trade and international financial hub, Hong Kong has an advanced level of openness. The regional environment can benefit enterprises not only has great connectivity in hard facilities such as accommodation and transportation, but interconnected legal rules in soft environment.

Potential opportunities for enterprises exist in their improvable parts, structural changes in household consumption, and underdeveloped market. In order to immediately respond to consumer needs, enterprises can establish a model of tourist satisfaction based on actual conditions and regularly investigate to get feedbacks for improving service quality. The increment in per capita disposable income indicates the improvement of the household consumption freedom in the region, cultivating tourism hotspots to inject vitality into the region [21]. In terms of industry status, compared with Lingnan Group and OCT, the proportion of the same enterprises as CT HK output value in its region GDP is lower. The development dimension's element index is shown in Figure 6.

In the comprehensive comparison of each dimension layer, the final competitiveness index of the enterprises is shown in Figure 7. The result shows that Lingnan Group needs to be upgraded in aspects of financial operation and cultural creativity. OCT is the most competitive cultural tourism enterprise among 


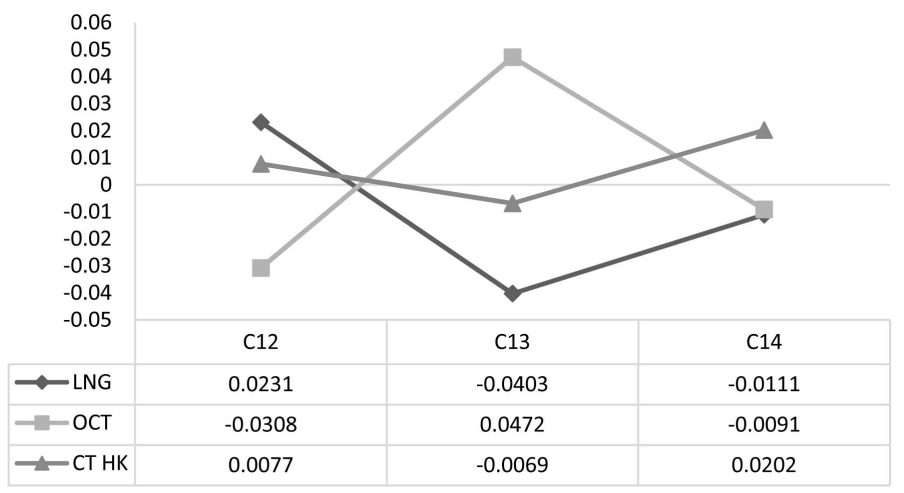

Figure 5. The element index of enterprise environmental layer.

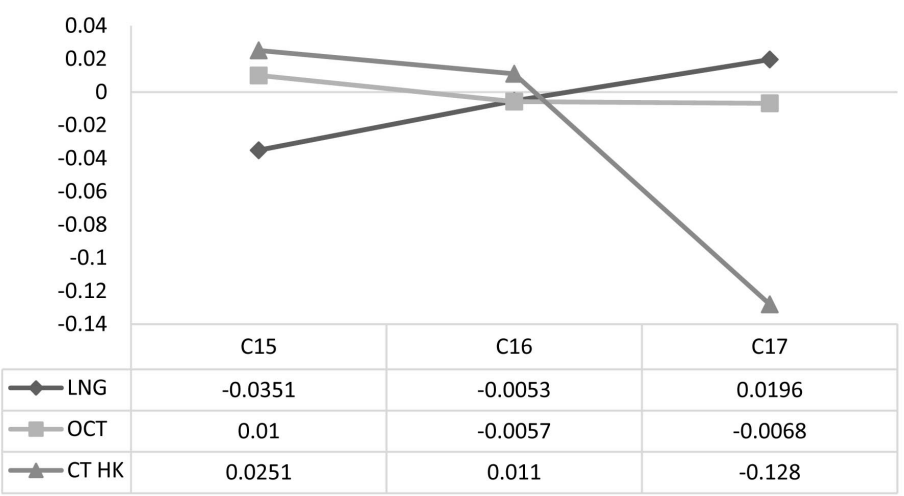

Figure 6. The element index of enterprise development layer.

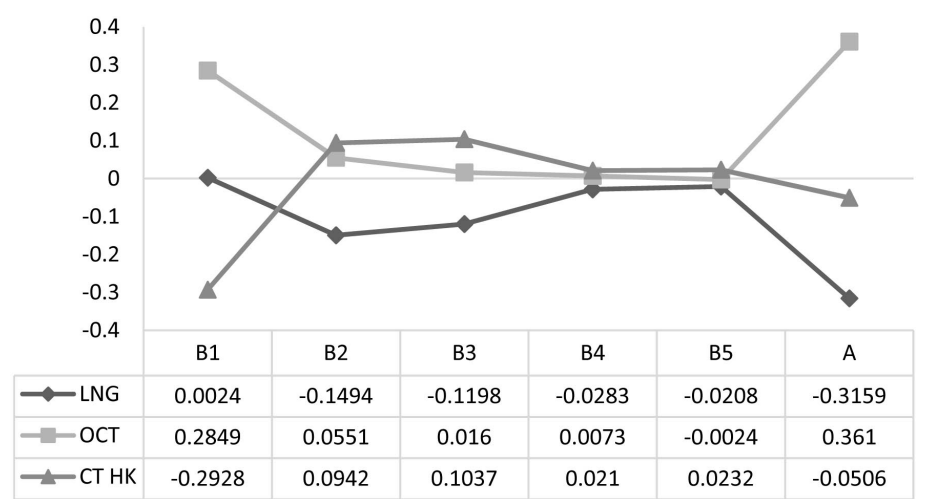

Figure 7. The dimension index of enterprise comprehensive competitiveness.

the three due to its resource superiority and steady performance at all layers. CT HK has a weakness at resource endowment layer, the enterprise therefore needs to actively engage in the joint construction of Guangdong-Hong Kong-Macao Greater Bay Area and strengthen its interactive cooperation with core and important node cities.

\section{Conclusions}

In the social environment of cross-industry integration, culture is no longer merely an ideology, but an energizing tool that integrates deeply with tourism. 
Relying on the various resources, the cultural tourism enterprises use culture as the core to accomplish in-depth social and commercial value through technology and satisfy consumer demands [22]. Industry tycoons are experiencing transformation and upgrading, iterating market, products, and customer relationship such as investment project cooperation, increasing online marketing channels, and enhancement of user experience, which is indispensable for them maintaining their competitiveness and playing a leading role [23]. Enterprises can tackle with the difficulty in financing through "culture plus finance". For example, the establishment of Cultural Property Exchange and China Cultural Industry Investment Fund, and the International Cultural Industry Fair held in Shenzhen where sets up a procurement negotiation area for overseas enterprises converging with culture and capital.

The research objects reflect the obvious obstacles in the flow of production factors, urban transformation in the Bay Area needs driving forces. In Guangdong Province, Guangzhou is the economic and international trade center. Shenzhen has obvious advantages in emerging industries and technological innovation. The Pearl River Delta region is the world's manufacturing base. Compared with Hong Kong and Macao, Guangdong still has space for improvement in marketization and internationalization. Although Hong Kong and Macao have a superior geographical position and the open market, Hong Kong's economic growth lacks stable endogenous force that local enterprises don't have sufficient long-term investments, leading to an industrial vacancy which needs higher quality or high-tech businesses to fill after the traditional manufacturing transfer. Macao also faces problems such as a single industrial structure, a cramped development space, and insufficient human resource. In order to improve the efficiency of internal combination, the government should play a leading role in the connection of infrastructures and the simplification of clearance policies, such as the "144-Hour Facilitation Visa" implemented in 2019, creating new model for clearance with a view to making better use of the Guangzhou-Shenzhen-Hong Kong Express Rail Link and the Hong Kong-Zhuhai-Macao Bridge, finally realizing multi-layer and borderless development of cultural tourism enterprises.

This research has certain limitations. First, partial qualitative indexes cannot fully quantify. Therefore, in the future, a unified big data platform can be established which uses advanced information technology to facilitate rational business administration. Second, as a matter of fact that the enterprise competition is dynamic, the research does not give a horizontal comparison of this dynamic state from different time periods. Subsequent research will monitor the performance of the cultural tourism enterprises during the implementation process of Outline Development Plan for the Guangdong-Hong Kong-Macao Greater Bay Area, improve each measurement index by adding in small and medium enterprise cases, analyze the constructed index system's fitness to cultural tourism enterprises in other regions, making it more scientific and systematic. 


\section{Conflicts of Interest}

The authors declare no conflicts of interest regarding the publication of this paper.

\section{References}

[1] The Fourth Session of the 12th National People's Congress. The 13th Five-Year Plan for Economic and Social Development of the People's Republic of China.

[2] The State Council of the People's Republic of China. Outline Development Plan for the Guangdong-Hong Kong-Macao Greater Bay Area.

[3] Xu, C. and Ye, L. (2008) An Empirical Analysis of the Comparison of Dynamic Competitiveness of China's Tourism Listed Companies. Tourism Tribune, 23, 28-32.

[4] Gao, L. and Zhang, W. (2008) Comprehensive Evaluation System of the Competitiveness of Tourism Listed Companies. Science and Technology Economic Market, No. 9, 9-11.

[5] Ge, H. (2008) Evaluation of the Competitiveness of Tourism Enterprises. Accounting and Finance, No. 5, 91-94.

[6] Xie, Y., Xiao, G. and Fu, J. (2010) ANP-Based Evaluation Model of Tourism Enterprise Competitiveness. The 5 th Chinese Academy of Management Annual Meeting Entrepreneurship and SME Management Parallel Session, Dalian, 13 November 2010, 39-48.

[7] Li, J., Zhang, H. and Zhang, C. (2011) Evaluation of the Competitiveness of Tourism Listed Companies Based on Entropy Weight Grey Correlation. Travel Forum, 4, 49-54.

[8] Zhang, G. and Liang, Q. (2011) Analysis of the Competitiveness of Tourism Enterprises in Shandong Province. Shandong Economy, No. 4, 129-133.

[9] Yu, Y. and Luo, L. (2014) Empirical Analysis of the Competitiveness of Online Tourism Enterprises Based on Entropy Weight TOPSIS Method. Journal of Hunan University of Finance and Economics, No. 4, 78-86.

[10] Porter, M.E. (1997) The Competitive Advantage. Chen Xiaoyue Translated, Huaxia Publishing House, Beijing.

[11] Wernerfelt, B. (1984) A Resource-Based View of the Firm. Strategic Management Journal, 5, 171-180. https://doi.org/10.1002/smj.4250050207

[12] Barney, J. (1991) Film Resources and Sustained Competitive Advantage. Journal of Management, 17, 99-120. https://doi.org/10.1177/014920639101700108

[13] Collis, D.J. and Montgomery, C.A. (1995) Competing on Resources: Strategy in the 1990s. Harvard Business Review, 73, 118-128.

[14] Prahalad, C.K. and Hamel, G. (1990) The Core Competence of the Corporation. Harvard Business Review, 68, 79-91.

[15] Chandler, G.N. and Hanks, S.H. (1994) Founder Competence, the Environment, and Venture Performance. Entrepreneurship Theory and Practice, 18, 77-90. https://doi.org/10.1177/104225879401800306

[16] Hamel, G. and Heene, A. (1994) Competence Based Competition. John Wiley Press, New York.

[17] Jin, P. (2003) Competitiveness Economics. Guangdong Economy Publishing House, Guangzhou.

[18] Jin, P. and Gong, J. (2014) Economic Trend, Policy Regulation and Their Impact on 
Enterprise Competitiveness: An Empirical Analysis Based on Panel Data of Chinese Industry. China Industrial Economics, No. 3, 5-17.

[19] Hu, P., Wen, C. and Pan, D. (2013) Research on the Relationship between External Network, Internal Resources and Enterprise Competitiveness. Science Research Management, No. 4, 90-98.

[20] Gao, J. and Zhang, L. (2017) Research on the Relationship between Tourism Industry Cluster, Total Factor Productivity and Tourism Economy in China. Resource Development and Market, 33, 1005-1010.

[21] Yang, F. and Wang, Y. (2018) Exploring the Cultural Tourism Construction of the "Internet Plus" Characteristic Town in Zhuhai in the Context of Gungdong-Hong Kong-Macao Greater Bay Area. Journal of Zhuhai Administrative College, Zhuhai Municipal Party Committee, No. 5, 69-75.

[22] Zhou, J. (2012) Research on Innovation System and Efficiency Evaluation of Cultural Industry. Nanjing University, Nanjing.

[23] Huang, X. and Zou, K. (2016) The Integration and Development of Culture, Business and Tourism in Guangdong-Hong Kong-Macao Greater Bay Area under the Strategic Background of the Belt and Road. Journal of South China Normal University (Social Science Edition), No. 4, 106-110. 